\title{
DOIS MESTRES NA PERIFERIA DO CAPITALISMO: Michael Löwy e Mariátegui
}

\author{
Ruy Braga* \\ Deni Alfaro Rubbo**
}

\begin{abstract}
O objetivo deste artigo é discutir alguns dos desdobramentos da interpretação da teoria do desenvolvimento desigual e combinado do capitalismo, presente em várias passagens da obra de Michael Löwy, a fim de indicar sua importância para a renovação crítica do marxismo latino-americano. Para tanto, buscaremos avançar por três momentos: 1) em primeiro lugar, iremos apresentar os delineamentos gerais da teoria do desenvolvimento desigual e combinado na obra de Löwy; 2) na sequência, vamos destacar a importância do contexto histórico latino-americano entre os anos de 1959 e 1979 no esforço interpretativo e político de Löwy, balizado, sobretudo, pela atualização da teoria do desenvolvimento desigual e combinado; finalmente, 3) argumentaremos que a fecundidade da interpretação de Löwy, no tocante ao contexto latino-americano, advém de sua familiaridade com o pensamento do marxista peruano José Carlos Mariátegui.

Palavras-chavE: Löwy. Mariátegui. Marxismo. Sociologia. América Latina.
\end{abstract}

\section{INTRODUÇÃO}

O objetivo deste artigo é discutir alguns dos desdobramentos da interpretação da teoria do desenvolvimento desigual e combinado do capitalismo, presente em várias passagens da obra de Michael Löwy (1938-), a fim de indicar sua importância para a renovação crítica do marxismo latino-americano. Para tanto, buscaremos avançar por três momentos: 1) em primeiro lugar, iremos apresentar os delineamentos gerais da teoria do desenvolvimento desigual e combinado na obra de Löwy; 2) na sequência, vamos destacar a importância do contexto histórico latino-americano entre os anos de 1959 e 1979 no esforço interpretativo e político de Löwy, balizado, sobretudo, pela atualização da teoria do desenvolvimento desigual e combinado; finalmente, 3) argumenta-

${ }^{*}$ Universidade de São Paulo (USP). Departamento de Sociologia.

Av. Professor Luciano Gualberto, 315. Cidade Universitária. Cep: 05508-080. São Paulo - São Paulo - Brasil. ruy.braga@uol.com.br

** Universidade de São Paulo (USP)

Av. Professor Luciano Gualberto, 315. Cidade Universitária. Cep: 05508-080. São Paulo - São Paulo - Brasil. deni_out27@uol.com.br remos que a fecundidade da interpretação de Löwy, no tocante ao contexto latino-americano advém de sua familiaridade com o pensamento do marxista peruano José Carlos Mariátegui (1894-1930), cuja obra é por ele estudada sistematicamente, desde, ao menos, meados dos anos 1970.

Trata-se de uma familiaridade que revela muito da agenda investigativa construída por Michael Löwy ao longo de mais de cinco décadas. Afinal, seu engajamento na reconstrução crítica do marxismo como um programa aberto de investigação comprometido com as lutas de emancipação não é novidade. Desde muito jovem, acantonado na esquerda antistalinista, Löwy encarnou como poucos a vitalidade da tradição do marxismo crítico, seja por meio de sua análise das revoluções sociais no século XX, seja mediante a difusão de autores marxistas da América Latina que empregaram, direta ou indiretamente, esse recurso analítico. Nessa trajetória, é de se destacar como a interpretação empreendida por Löwy da obra de José Carlos Mariátegui sobre a formação social peruana e as comunidades indígenas serviu como demonstração da vitalidade da tradição 
crítica do marxismo no tocante à análise das sociedades pós-coloniais e (semi) periféricas.

No entanto, apesar da importância do pensamento de Mariátegui na reconstrução crítica que Löwy realizou da teoria do desenvolvimento desigual e combinado, vale destacar que a matriz que inspirou originalmente sua abordagem não passou pelo marxista peruano. "Homem de muitos mundos", tal qual diria Boff (2007, p. 15), Michael Löwy nasceu no Brasil, onde se tornou militante socialista e iniciou sua trajetória como um dos mais renomados teóricos marxistas vivos. Por meio de seus estudos dedicados a autores como Karl Marx, Che Guevara, Antonio Gramsci, Rosa Luxemburgo, Georg Lukács, Lucien Goldmann e Walter Benjamin, Löwy soube revelar, empregando o instrumental da crítica cultural materialista e da sociologia da religião, dilemas, impasses e atualizações da teoria crítica frente a diferentes transições históricas promovidas pelo capitalismo contemporâneo. ${ }^{1}$

De família de judeus imigrantes, Löwy formou-se no curso de Ciências Sociais da Universidade de São Paulo (USP). Foi aluno de expoentes da sociologia brasileira, como Florestan Fernandes, Octávio Ianni, Antonio Candido, Fernando Henrique Cardoso, Aziz Simão, dentre outros. Uma curiosidade desse $\stackrel{\infty}{\overrightarrow{0}}$ percurso, conforme observa Ridenti (2007, p. จ 170-171), é que “... sua obra nunca tenha se $\underset{1}{\perp}$ debruçado mais detidamente sobre a sociedade brasileira, nem sobre qualquer intelectual conterrâneo", ainda que se possa notar a influência de Caio Prado Júnior em alguns de seus trabalhos (Löwy, 2004, p. 11).

Apesar disso, Löwy tem demonstrado, $\therefore$ ao longo das décadas, um cuidado muito esके pecial com os temas latino-americanos. Como $\rightarrow$

Sociólogo público “internacionalista”, sempre atento às possibilidades da emancipação em escala planetária, ๙ L Löwy notabilizou-se como intérprete do ideário da es- querda contemporânea, sendo improvável que algum es-

Tudante de Ciências Sociais desconheça, ao menos, um de

త seus trabalhos. Com uma produção teórica que remonta

ao início da década de 1960, ele é autor de dezenas de

livros e centenas de ensaios, traduzidos em mais de vinte

e cinco idiomas, alcançando uma rara consagração entre seus pares. observa Antunes (2007, p. 20), a vida no Norte global não fez com que Löwy abdicasse de sua "alma latino-americana". Não custa lembrar que ele fez parte de uma geração que, em grande medida, ligou-se politicamente à trajetória e ao destino da Revolução Cubana. Nas palavras de Emir Sader: "Um processo heterodoxo como o cubano trazia a atualidade da revolução até nós, e nos chegava pelas mãos do Michael, que teve toda sua trajetória ligada ao socialismo, à confiança na revolução, à ética revolucionária, à indissolubilidade entre teoria e prática" (Sader, 2007, p. 164).

$\mathrm{Na}$ realidade, conforme afirma o próprio Löwy, “... a espetacular radicalização da Revolução Cubana e sua opção socialista em 1960-1961 fizeram de Cuba, durante muitos anos, um componente essencial do coquetel marxista com que se nutriu toda minha geração" (2004, p. 11). Não foi por acaso que ele dedicou parte de sua produção intelectual à história do pensamento marxista latino-americano, especialmente às trajetórias de Che Guevara (1928-1967) e de José Carlos Mariátegui. ${ }^{2}$ Posteriormente, tendo em vista seu projeto de reconstruir o marxismo a partir da corrente do romantismo revolucionário, ele buscou igualmente identificar algumas afinidades e influências entre o cristianismo da libertação, muito presente na América Latina, e a tradição marxista (Löwy, 2000). ${ }^{3}$

Neste sentido, Löwy interessou-se pelo ativismo histórico dos movimentos camponeses e indígenas, em especial, pela trajetória do Exército Zapatista de Libertação Nacional (EZLN) e do Movimento dos Trabalhadores Rurais Sem Terra (MST) (Löwy, 2007). Para

\footnotetext{
${ }^{2}$ Doravante JCM.
}

${ }^{3}$ Para Traverso (2012), a relação constituída entre a trajetória intelectual de Michael Löwy e a cultura latino-americana se divide em três momentos: o impacto do guevarismo como corrente "voluntarista" tanto no plano ético como político; a obra de Mariátegui, para quem o "marxismo deixou de ser um produto importado para criar raízes na cultura do continente e se tornar uma expressão autêntica"; e a teologia da libertação, que encontrou uma "síntese entre socialismo e a ética anticapitalista que anima as comunidades de base da igreja católica". Ver também Dianteill (2012, p. 55-57), que apontou três constelações na trajetória de Löwy: a judeu-germânica, a romântica-surrealista e a "revolucionária latino-americana" 
ele, em larga medida, esses fenômenos políticos contemporâneos revelam não apenas a reprodução das tensões do capitalismo na semiperiferia como também a atualidade da crítica marxista das ideologias do progresso social que enrijeceram as experiências políticas stalinista e socialdemocrata ao longo do século XX.

Da perspectiva de sua visão política de mundo, Löwy mostrou-se sempre um socialista preocupado com a dimensão internacionalista das lutas sociais, atuando na criação da Liga Socialista Independente (LSI), em 1955, junto a militantes "luxemburguistas", entre os quais se destacavam Paul Singer e Maurício Tragtenberg. No início década de 1960, ele participou da fundação da Organização Revolucionária Marxista "Política Operária” (Polop), agrupamento político anticapitalista formado por estudantes e militares de baixa patente, que se propôs a disputar a hegemonia com o Partido Comunista Brasileiro (PCB).

Em Paris, ele ingressou na Ligue Communiste Révolutionnaire (LCR), seção francesa da Quarta Internacional, relacionando-se ativamente com o trotskismo. A "paixão amorosa, política e intelectual” por Rosa Luxemburgo (cf. Loureiro, 2007), a fascinação pelo espírito e pela imaginação rebelde surrealista, a intimidade com o pensamento de Leon Trotsky e a influência da sociologia marxista da cultura de Lucien Goldmann (com quem foi para a França fazer sua tese de doutorado) demonstraram, ao longo dos anos, seu compromisso com a reconstrução crítica do marxismo, capaz de inspirar um programa investigativo à altura das antinomias produzidas pela reprodução das contradições capitalistas na contemporaneidade.

\section{CONVERGÊNCIAS E COMPLE- MENTARIEDADES}

Esse programa investigativo apoiou-se em uma abordagem antiteleológica das lutas de classes, inspirada na teoria do desenvolvimento desigual e combinado do capitalismo, que buscou valorizar as bifurcações e as encruzilhadas da história. Trata-se de um antídoto para as análises "etapistas" e "dualistas" que interpretaram o progresso da história em termos de avanços e recuos sobre um mesmo eixo cronológico pré-determinado. Uma das teses mais problematizadas pela economia e pela sociologia marxistas, a teoria do desenvolvimento desigual e combinado, além de inspirar uma interpretação renovada do imperialismo, foi também responsável por romper com o evolucionismo, a ideologia do progresso e o eurocentrismo, muito comuns no marxismo no pós-Segunda Guerra Mundial (Löwy, 1998, p. 73).

Aqui, vale lembrar que Löwy avançou em paralelo a outros autores brasileiros que também incorporaram a teoria do desenvolvimento desigual e combinado em suas interpretações de fenômenos sociais tipicamente semiperiféricos, como Francisco de Oliveira e Francisco Weffort, por exemplo. Tratava-se de um amplo esforço de interpretação das especificidades do modo de reprodução do capitalismo na semiperiferia. Esse estilo de análise rompeu com as abordagens dualistas que superestimavam a presença dos resíduos tradicionais no processo de formação da classe operária brasileira. Em suma, uma nova teoria sobre a reprodução contraditória do capitalismo na periferia surgiu do esforço reflexivo mais ou menos coordenado desses autores.

Em sua crítica à razão dualista, por exemplo, Oliveira (2003) partiu de uma afirmação bastante inusual a respeito da resiliência da economia de subsistência nas cidades: ao comprimir os custos de reprodução da força de trabalho, os vestígios rurais no contexto urbano potencializariam a acumulação de capitais. Resultado da combinação de nossa herança rural com a superexploração do trabalho, a precariedade seria inerente ao modelo de desenvolvimento fordista periférico. Retornando ao capítulo XXIV de $O$ capital, o modelo agrícola brasileiro foi reavaliado à luz da acumulação primitiva, ou seja, como apropriação de excedentes não mercantis. 
Em suma, para Chico de Oliveira, o modo de regulação do pós-Segunda Guerra no Brasil teria identificado, na incorporação das classes trabalhadoras ao compromisso populista, uma oportunidade de mitigar a resistência dos proprietários rurais à expansão da indústria. No entanto, eles não foram afastados, nem da estrutura do poder, nem dos benefícios trazidos pela industrialização. Conforme Chico de Oliveira, ao contrário do capitalismo avançado, o fordismo periférico brasileiro não "destruiu completamente o antigo modo de acumulação”.

Esse tipo de relação nutriu-se da crise de legitimidade dos grupos dominantes após a Revolução de 1930: nem os decadentes setores cafeeiros, nem as frágeis classes médias, nem os incipientes grupos industriais lograram construir uma hegemonia capaz de totalizar seus interesses classistas. Conforme Weffort, surgiu, nesse contexto, a "única fonte de legitimidade possível ao novo Estado brasileiro", ou seja, as massas urbanas. Da necessidade de superar a crise de legitimidade do Estado adveio a principal característica da regulação populista: incorporar em parte, frustrando progressivamente, as expectativas populares despertadas pela modernização social.

A exemplo de Chico de Oliveira, Weffort $\infty$ (2008) interpretou a relação do moderno com ลิ o arcaico não como uma exterioridade confliti$\stackrel{\infty}{\infty}$ va, mas como uma unidade contraditória. Assim, ele enfatizou a importância da ação das massas populares numa fase da história brasileira em que predominava um modo de regulação formalmente democrático. Daí sua ênfase $\dot{\infty}$ na função de intermediação da estrutura sindical entre o poder político e a classe operária. Ao representar certas reivindicações econômicas dessa classe junto ao poder político e, ao mesmo tempo, representar o poder político junto ao operariado, Weffort revelou a força da “pressão" dos subalternos sobre o Estado.

Em sua opinião, a democracia brasileira, sob o populismo, estaria deixando de ser uma simples formalidade, como o fora durante a República Velha, para se tornar algo novo: uma "revolução democrática". No entanto, se o populismo resultou das pressões dos trabalhadores sobre o Estado, ele seria, igualmente, o produto da "traição das massas populares" por governos incapazes, tendo em vista as limitações do fordismo periférico de cumprir suas promessas reformistas. Por sua vez, essa "traição" alimentaria novas pressões, e assim sucessivamente. A complementariedade existente entre Chico de Oliveira e Francisco Weffort deriva tanto de sua crítica da ideologia da modernização, própria às abordagens dualistas, quanto da problematização da relação entre a particularidade do capitalismo brasileiro e a universalidade do mercado mundial.

É possível perceber uma aguda relação de afinidade que enlaça as interpretações de Chico de Oliveira, de Francisco Weffort e de Michael Löwy, inspirados pela teoria do desenvolvimento desigual e combinado, sobre a reprodução do capitalismo na semiperiferia latino-americana. No início dos anos 1980, Löwy publicou dois trabalhos dedicados à história das ideias marxistas nas sociedades periféricas. O primeiro deles foi Le marxisme en Amerique Latine, uma antologia de escritos marxistas latino-americanos, publicada em francês, logo traduzida para o espanhol e, finalmente, para o português, que continha uma exaustiva introdução dedicada à especificidade do marxismo latino-americano (Löwy, 2006). Logo depois, Löwy sistematizou suas reflexões sobre a teoria do desenvolvimento desigual e combinado no volume intitulado The Politics of Combined and Uneven Development, originalmente uma encomenda do historiador britânico Perry Anderson, ${ }^{4}$ onde descortinou o desenvolvimento teórico da revolução permanente nos países capitalistas semiperiféricos,

4 Michael Löwy, em correspondência com Deni Alfaro Rubbo, em agosto de 2015. Por conta da pesquisa de Doutorado desenvolvida atualmente no Programa de Pós-Graduação em Sociologia da USP por Deni Alfaro Rubbo e orientada por Ruy Braga, os autores deste artigo têm dialogado de forma intensa com Michael Löwy a respeito de sua trajetória e de sua produção teórica. Com a devida autorização de Löwy, trechos desses diálogos serão citados no presente artigo. 
assim como empreendeu uma análise concreta das diversas revoluções socialistas do século XX (Löwy, 2015).

Nesse último livro, é possível registrar a elaboração de uma visão dialética do processo histórico do "marxismo aberto" de Leon Trotsky, diante de sua análise sobre a formação social russa, marcada por "saltos súbitos", "fusões contraditórias" e "combinações inesperadas". Assim, com a difusão mundial do capitalismo a partir do século XVII, as nações capitalistas periféricas foram sendo plasmadas a partir da combinação de temporalidades heterogêneas, que atendiam aos litígios do capitalismo internacional, fundadas na contradição existente entre os processos internos e as forças externas do desenvolvimento capitalista mundial.

Segundo Löwy, as características metodológicas que embasavam a teoria da revolução permanente de Trotsky eram: a adoção do ponto de vista da totalidade para a análise dialética do mercado mundial e da luta de classes em escala nacional (Löwy, 2014, p. 68); o caráter aberto da historicidade social, atrelado a uma concepção crítica e dialética do desenvolvimento histórico (Idem, p. 70); a síntese entre o particular e o universal na formação das tendências gerais do desenvolvimento capitalista. De uma perspectiva estratégica, Trotsky construiu, sob a hegemonia proletária, um programa político que combinava medidas democráticas, nacionais e socialistas, ou melhor, uma transição ininterrupta da revolução democrática para a socialista.

\section{TEORIA E HISTÓRIA}

Vale mencionar que, no mesmo período em que Löwy publicou seus estudos sobre a América Latina contidos no livro dedicado à teoria do desenvolvimento desigual e combinado, o processo da revolução sandinista inspirava o imaginário político e intelectual da esquerda latino-americana, assim como outras revoluções políticas ocorridas em países da periferia permaneciam em aberto, carentes de um balanço cabal a respeito de seus desdobramentos. Em certo sentido, trata-se de uma das características do desenvolvimento desigual e combinado: países periféricos podiam se transformar na vanguarda de transformações futuras. Isso fez com que Löwy elaborasse uma análise comparativa das revoluções em curso entre diferentes países (Iugoslávia, China, Cuba, Vietnã e Nicarágua) (Löwy, 1998, p. 78). Comentando o livro de Löwy, Roberto Schwarz contextualizou o alcance e os limites dessa empreitada:

Pois bem, até os anos 1970, a série das revoluções em países periféricos pareceu dar certa razão a Trotsky, no que respeita à conquista do poder. Na etapa subsequente, contudo, quando se tratava de construir a sociedade superior e alcançar o bem-estar dos países adiantados, o peso do determinismo econômico reapareceu com toda força, ao passo que o voluntarismo revolucionário se mostrou insuficiente. Enquanto o desenvolvimento desigual e combinado do capitalismo se renovava e se aprofundava velozmente, a política da revolução permanente chegava a um impasse, menos porque fosse impensável o assalto ao poder por uma vanguarda, e mais porque o caminho ulterior em direção do socialismo parecia bloqueado (Schwarz, 2007, p. 160).

Mesmo com as revoluções periféricas abortadas, o desafio do desenvolvimento desigual e combinado mostrou-se um recurso analítico produtivo para interpretar diferentes contextos nacionais periféricos. Tendo em vista o advento do neoliberalismo e da globalização capitalista nos anos 1970 e 1980, é possível afirmar que se trata de uma teoria que foi se transformando em um instrumento de análise cada dia mais fecundo. Uma vitalidade que pode ser observada na forma como Löwy interpretou a história das idéias políticas e de desenvolvimentos teóricos do marxismo latino-americano no século XX a partir do tema da revolução na periferia do capitalismo, "incorporando documentos de diferentes correntes do marxismo [...], inclusive das correntes minoritárias, esquecidas pela história oficial dos universitários (e pela dos partidos comunistas)" (Löwy, 2006, p. 65). 
Por resgatar a importância analítica e política de autores e correntes minoritárias e subterrâneas do marxismo latino-americano, o trabalho de Löwy compôs um painel de espaços políticos acirrados, desiguais e combinados, tanto na formulação de estratégias e táticas políticas quanto na análise das diferentes formações sociais do continente. Para o sociólogo crítico, no plano das ideias políticas, a controvérsia central na história do marxismo latino-americano oscilou entre a perspectiva eurocêntrica e o ponto de vista "concreto-dialético", "deixando de lado o eclético e exótico indo-americanismo, que tende a ultrapassar as fronteiras do marxismo" (Löwy, 2006, p. 13).

Como foi destacado acima, pelas características que a definem como matriz teórica explicativa, a teoria do desenvolvimento desigual e combinado encontrou abrigo na posição “dialético-concreta” identificada por Löwy. A corrente eurocêntrica, caracterizada pelos PCs, que se esforçou em transpor mecanicamente para a realidade latino-americana uma versão rígida e unilateral do "modelo de desenvolvimento" europeu ocidental, revelou-se pouco instrumentalizada para dar conta das características da reprodução do capitalismo na periferia, em especial quando pensamos na relação entre o nacional e o internacional, além $\stackrel{\infty}{\Xi}$ das implicações da reprodução das diferentes N . temporalidades sociais para a trajetória dos $\dot{8}$ processos de proletarização e de formação da estrutura de classes no continente.

As críticas à noção de "burguesia nacional", à doutrina do "feudalismo" e aos esquemas etapistas e dualistas que caracterizavam $\dot{s}$ o marxismo oficial latino-americano eram voz corrente na esquerda antistalinista. O pioneii rismo revelou-se nas análises de trotskistas brasileiros, como o trabalho "Esboço de uma análise da situação econômica e social do Brasil”, de Mario Pedrosa e Lívio Xavier (1930). Na historiografia, o debate da natureza capitalista ou semifeudal da economia colonial esteve no cerne das controvérsias teóricas e políticas na América Latina. Trabalhos sobre a formação histórica das classes sociais, com a articulação entre traços semifeudais e capitalistas, do historiador brasileiro Caio Prado Júnior (1951), do argentino Sérgio Bagu (1949) e do chileno Marcelo Segall (1953) são outros bons exemplos. Segundo Milcíades Peña (1957) e Luís Vitale (1966), “... vão utilizar a teoria do desenvolvimento desigual e combinado para analisar a articulação entre elementos escravistas ou semifeudais com o capitalismo, sempre insistindo sobre a predominância deste último" (Löwy, 1998, p. 80).

Contudo a interpretação da realidade latino-americana a partir da teoria do desenvolvimento desigual e combinado não se limitou à influência sobre os trotskistas e os historiadores latino-americanos. Para Löwy, foi o advento da Revolução Cubana que abriu uma verdadeira brecha na história do marxismo latino-americano a partir de uma grande transformação da história do subcontinente. Em poucas palavras, aos olhos do sociólogo marxista, o processo cubano demonstrou: “... a possibilidade objetiva de uma revolução combinar tarefas democráticas e socialistas em um processo revolucionário ininterrupto" (Löwy, 2006, p. 45, grifos do autor).

Em certa medida, a Revolução Cubana representou o estímulo necessário ao desenvolvimento de uma ciência social marxista criativa nas universidades latino-americanas. No esforço de atualização do instrumental teórico marxista e sob os mais diferentes campos temáticos de pesquisa (movimento operário, sindicalismo, populismo, marginalidade, dependência e subdesenvolvimento, questão agrária etc.), autores latino-americanos dedicaram-se a decifrar a especificidade da reprodução contraditória das relações de produção capitalistas em seus respectivos países. ${ }^{5}$

Muitos deles serviram-se, de forma mais ou menos explícita, da teoria do desenvolvimento desigual e combinado, a fim de

${ }^{5}$ Para uma análise sobre a influência da lei do desenvolvimento desigual e combinado nos intelectuais brasileiros, ver Demier (2007). 
caracterizar as particularidades das formações sociais em questão, incrementando a interpretação das possibilidades abertas pelos diferentes movimentos sociais de emancipação que se espalharam pelo continente (Löwy, 1998, p. 79). Evidentemente, tratava-se de um conjunto de autores (Rodolfo Stavenhagen, Florestan Fernandes, André Gunder Frank, Ruy Mauro Marini, Aníbal Quijano, Octávio Ianni, Chico de Oliveira, etc.) que se manteve distante tanto das ideologias da modernização social, inspiradas pelo dualismo (atrasado e moderno) cepalino, quanto do empobrecedor etapismo stalinista. ${ }^{6}$

\section{MICHAEL LÖWY E JOSÉ CARLOS MARIÁTEGUI}

Para Löwy, a teoria do desenvolvimento desigual e combinado teve em José Carlos Mariátegui seu principal intérprete latino-americano. Nascido em Moquegua em 1894, “ Mariátegui trabalhou como jornalista durante toda sua trajetória. Após um efêmero interesse pela atividade artística e pela vida boêmia, o jornalista peruano autodidata se aproximou das ideias socialistas em 1918, no contexto da reivindicação do movimento estudantil pela reforma universitária, das greves dos operários pela redução da jornada de trabalho em Lima, e da eclosão da Revolução Bolchevique.

Entre 1919 e 1922, período em que esteve na Europa, particularmente na Itália, Mariátegui consolidou suas posições socialistas, amadureceu sua percepção política e aprofundou seu conhecimento teórico a respeito, em particular, do fascismo. Ademais, aproximou-se da literatura marxista clássica (Marx, Engels, Lênin, Trotsky) e acompanhou o destino da Internacional Comunista e de seus principais atores políticos. Entrementes, o marxista peruano demonstrou interesse pelo debate intelectual que transcorria na Itália, especial-

${ }^{6}$ Para uma crítica das teorias decoloniais a partir de uma matriz inspirada em Mariátegui e Quijano, ver Cahen e Braga (2018). mente através das figuras de Piero Gobetti e Benedetto Croce, além do recém-criado Partido Comunista Italiano (fundado em 1921) e seu jornal L'Ordine Nouvo. ${ }^{7} \mathrm{Na}$ França, aproximou-se da obra de Georges Sorel e de sua elaboração a respeito do mito revolucionário. ${ }^{8}$

Após seu retorno ao Peru, Mariátegui começou a desenvolver uma ampla reflexão teórica somada a um projeto de organização cultural e política no país. Assim, ele foi convidado a proferir um curso sobre atualidade política internacional na Universidade Popular González Prada, no mesmo momento em que passou a integrar as fileiras da Aliança Popular Revolucionária Americana (APRA) - movimento continental anti-imperialista liderado por Víctor Raul de la Torre; finalmente, ele fundou a revista Amauta (1926), espaço que reuniu a vanguarda cultural e política do Peru e da América Latina em suas páginas.

Em 1927, acusado de participar de uma “conspiração comunista”, Mariátegui foi preso em um hospital militar pelo governo. Um ano depois, rompeu com a APRA e ajudou a fundar o Partido Socialista Peruano (PSP), tornando-se membro da III Internacional. Logo em seguida, em 1928, ele publicou sua obra prima, isto é, os Siete ensayos de la interpretación de la realidad peruana. Nesse período, sua atividade política se intensificou: fundou a Confederação Geral dos Trabalhadores Peruanos (CGT) e o jornal Labor; enviou duas teses sobre a questão indígena e o imperialismo para a Primeira Conferência Comunista Latino-americana (Buenos Aires, 1929), recebendo duras críticas dos delegados alinhados à ortodoxia estalinista. Padecendo desde criança de uma saúde muito frágil - lembremos que ele foi obrigado, em 1924, a amputar a perna direita em decorrência de uma grave enfermidade -, Mariátegui morreu em 1930, aos 35 anos.

${ }^{7}$ Para informações sobre a estadia de Mariátegui na Europa, ver Beigel (2006) especialmente o cap. II, Melis (1999, p. 155-164), Nuñez (1994), Paris (1981, especialmente os cap. II e VI) e Vanden (1975, p. 25-83).

${ }^{8}$ Para um estudo sobre a importância de Georges Sorel em JCM, ver Salvatecci (1979). 
Mariátegui considerava o marxismo como um "método" flexível, aberto e crítico, e não como "uma corrente de princípios de consequências rígidas, iguais para todos os climas históricos e todas as latitudes sociais". Afinal, "em cada país, em cada povo, opera e atua sobre o ambiente, sobre o meio, sem descuidar de nenhuma de suas modalidades". (Mariátegui, 1988, p.112). É verdade que a expressão "desenvolvimento desigual e combinado" não se encontra presente em seus trabalhos. Não obstante, pode-se facilmente identificar a presença dessa teoria em seus artigos, em especial, na interpretação sobre a formação social peruana e o papel das comunidades rurais indígenas em um eventual processo revolucionário socialista.

Curiosamente, descortinar a especificidade histórica latino-americana não foi consequência das leituras marxistas de Mariátegui. Afinal, ele não conheceu a correspondência entre Marx e Vera Zasulich sobre a comuna rural russa. ${ }^{9}$ Tampouco travara contato com O desenvolvimento do capitalismo na Rússia de Lênin, Balanço e Perspectivas, A revolução permanente e História da Revolução Russa de Trotsky, os dois últimos publicados somente após a morte de Mariátegui. No entanto, ele conhecia vários escritos dos revolucionários russos disponíveis em sua biblioteca particular, escreveu sobre eles em algumas oportunidades e divulgou textos de Lênin e de Trotsky na revista Amauta (1926-1930), do qual foi diretor-chefe (para mais detalhes, ver Vanden, 1975). Apesar de sua intimidade com os revolucionários bolcheviques, deduzir mecanicamente sua interpretação da revolução peruana diretamente dos escritos de Lênin e Trotsky seria um equívoco. Na realidade, mais correto

${ }^{9}$ Descoberta depois da morte de Mariátegui, a correspondência entre Marx e Vera Zasulich - acerca da formação ๙ social russa e as condições de viabilidade ou não para - uma revolução socialista - revela uma leitura de Marx que,

IJ dentre outras questões, desvincularia a revolução socia-

J lista de um patamar necessário de desenvolvimento das

forças produtivas. Segundo Michael Löwy, esse conjunto

de textos significa "uma ruptura profunda com qualquer

interpretação unilinear, evolucionista, 'etapista' e eurocêntrica do materialismo histórico." (Löwy, 2013, p. 9). seria dizer que o marxismo de Mariátegui trilhou um caminho muito particular, ainda que influenciado pelo marxismo revolucionário.

Daí a importância da interpretação de Michael Löwy a respeito da obra do fundador do socialismo peruano: identificar a particularidade, localizando-a em um contexto intelectual e político mais amplo. A relação de Löwy com a obra mariateguiana remonta aos tempos de estudante universitário na USP, no final da década de 1950. Os primeiros contatos de Löwy com o pensamento de Mariátegui se deram por meio de fontes secundárias, opúsculos sobre o marxismo na América Latina, nos quais Mariátegui era citado de forma superficial. De qualquer maneira, o grande tema da especificidade da revolução socialista no subcontinente foi suficientemente forte para atrair a imaginação sociológica de Löwy, aproximando-o de Mariátegui. ${ }^{10}$

Interessante notar que a história da recepção do legado de JCM iniciou-se imediatamente depois de sua morte. Ainda que de maneira restrita, entre as décadas de 1930 e 1950 a obra mariateguiana contava, entre seus primeiros leitores, com intelectuais e militantes políticos - que disputavam, desde já, seu legado político e ideológico. Encerrada a fase de "liquidar o amautismo" levada a cabo pelo Partido Comunista Peruano (PCP) na década de 1930, além das críticas feitas por V. M. Miroshevski, membro da Internacional Comunista, que o acusa de "populista", Mariátegui passa a ser reivindicado pelo próprio PCP como um "stalinista avant la lettre", dentro de uma genealogia ortodoxa e rígida. Tratava-se de uma operação que visava a transformar o revolucionário peruano em um "marxista-leninista-stalinista”. Do outro lado da esquerda peruana, integrantes que compunham o Partido Nacionalista Aprista, liderados por Haya de la Torre, também reivindicavam a herança mariateguiana. As desavenças entre o pensamento de Mariátegui e de Haya passaram a ser mini-

${ }^{10}$ Michael Löwy, correspondência com Deni Alfaro Rubbo, agosto de 2017 . 
mizadas em contraposição às tensões entre o primeiro e a III Internacional. ${ }^{11}$

De todo modo, a circulação transnacional das ideias mariateguianas pela América Latina começou a ganhar um novo impulso a partir da publicação de suas Obras Completas, projeto iniciado em 1956, sob a tutela da família do autor. Editada em formato de bolso, a preços baratos e com altas tiragens, os livros foram publicados paulatinamente até 1970, circulando amplamente pelo continente (Pericás, 2011). Já o livro Sete ensaios teve uma circulação ainda mais ampla, sendo traduzido e (ou) editado em diversos países durante as décadas de 1960 e 1970: Chile (1955), Cuba (1963, 1969 e 1973), União Soviética (1963), França (1968 e 1977), México (1969, 1979 e 1988), Uruguai (1970 e 1973), Estados Unidos (1971, 1974 e 1988), Itália (1972), Bulgária (1977), Espanha (1976), Hungria (1977), Venezuela (1979, 1995, 2007).

No Brasil, a recepção de Mariátegui foi tímida, além de tardia. Segundo Pericás, o marxista peruano exerceu uma influência marginal, distante das atenções e das discussões do meio acadêmico ou dos ambientes partidários (Pericás, 2010). Apenas em 1975 o livro Sete ensaios foi publicado em português pela editora Alfa Ômega e prefaciado por Florestan Fernandes um atraso de mais de quarenta e sete anos.

Admirador confesso do autor peruano, o sociólogo paulista afirmou que “... as metas que [Mariátegui] se propõe explicitamente são as mesmas que iriam impor, reiteradamente, daí em diante, às varias gerações de cientistas sociais da América Latina” (Fernandes, 1975, p. XV). ${ }^{12}$ Não por acaso, justamente nesse momento é que Mariátegui passa a ser conhecido também no campo acadêmico, especialmente entre cientistas sociais engajados em iniciati-

\footnotetext{
${ }^{11}$ O tema da herança mariateguiana é trabalhado de forma pioneira por Aricó (1978), intelectual argentino que contribuiu de maneira decisiva ao reunir documentos raros sobre Mariátegui, demonstrando como as organizações políticas peruanas ora reivindicavam, ora repeliam seu legado.

${ }^{12}$ Para mais detalhes sobre o interesse de Florestan Fernandes por Mariátegui, ver Rubbo (2016).
}

vas políticas e culturais contra os regimes ditatoriais violentamente instaurados na América Latina. Nesse contexto, a sociologia crítica latino-americana alavancou temáticas semelhantes às do intelectual andino sobre a especificidade da construção de sociedade de classes na periferia capitalista, abordando questões como a dependência econômica, o papel do imperialismo e o caráter da burguesia. A circulação das ideias mariateguianas acerca da realidade latino-americana e suas peculiaridades, como a criação de uma versão autóctone de socialismo, "sem decalque nem cópia”, inseriu-se também em um processo de fertilização do marxismo na América Latina, junto com a difusão das obras de Gramsci e Lukács, por exemplo.

Não obstante, foi apenas nos anos 1970 que Michael Löwy começou, de fato, a estudar a obra do socialista peruano, o que ocorreu após adquirir a coleção das Obras Completas em uma de suas visitas ao México. ${ }^{13}$ Por conseguinte, Löwy não se aproximou de Mariátegui nem pela edição francesa de 1968, publicada por François Maspero (amigo de militância na LCR e que editaria alguns de seus trabalhos), nem pela edição brasileira prefaciada pelo seu antigo professor de sociologia durante o curso de ciências sociais na USP.

De qualquer maneira, houve um esforço por parte de Löwy para elevar Mariátegui à condição de um pensador do modo de reprodução do capitalismo na periferia, e não apenas como um intérprete da sociedade peruana. Ainda assim, como afirma o próprio Löwy, essa sua primeira apropriação de Mariátegui deixava de lado dimensões decisivas da obra do crítico peruano, em especial a questão da cultura e da religiosidade popular. ${ }^{14}$ Além dis-

${ }^{13}$ Michael Löwy, entrevista com Deni Alfaro Rubbo e Luiz Bernardo Pericás, novembro de 2012.

${ }^{14}$ Michael Löwy, entrevista com Deni Alfaro Rubbo e Luiz Bernardo Pericás, novembro de 2012. Para Löwy, na leitura realizada durante a década de 1970 , ao apropriar-se seletivamente dessa face política latino-americana de Mariátegui, deixava de lado a compreensão da dimensão cultural, do filósofo e do pensador universal do marxismo. A partir de seu projeto intelectual que assimila o componente romântico-revolucionário, essas dimensões culturais (como o surrealismo), filosóficas (a importância da ética na dimensão marxista), religiosas (a "mística" da luta), outrora 
so, muito da compreensão e interpretação de Löwy sobre Mariátegui passou pelo filtro de autores como José Aricó (1978), Alberto Flores Galindo ([1980]1994), Enrique Dussel (1990), Robert Paris (1966) e Jiménez Ricárdez (1978). Trata-se de um conjunto de trabalhos com objetivos e ênfases distintas, mas que coincidiam em situar Mariátegui no interior de uma tradição desviante em relação ao stalinismo.

Precursor de uma síntese dialética entre o universal e particular, tal como sustenta Michael Löwy (2006, p. 17), o escritor peruano, em seu mais influente volume, isto é, Sete ensaios de interpretação da realidade peruana (Mariátegui, 1969), desenvolveu pioneiramente uma análise marxista crítica de uma formação social latino-americana. A leitura a respeito da sociedade peruana baseava-se na unidade substantiva de uma temporalidade histórica plasmada por múltiplas determinações. Na proposta formulada no primeiro capítulo do livro ("Esquema da evolução econômica"), Mariátegui interpretou a formação histórico-social peruana ancorada numa perspectiva "estrutural, global e histórica” de elementos desiguais, contraditórios e combinados (Montiel, 1979). A originalidade teórica da experiência peruana decorria da coexistência de três economias diferentes: a economia "feudal", a "comunista indíœ gena” e a "burguesa” (Mariátegui, 1969, p. 28). ก A "semifeudalidade", a "servidão" e o “ “capitalismo” não constituiriam modos de produção separados atuando em um mesmo território. Na realidade, os modos de produção estariam enlaçados de maneira simultânea, apesar de seus ritmos sociais discordantes. i. Desse modo, os estudos de Mariátegui sobre o

¿ Peru apontavam para uma imbricação entre o के capitalismo, o feudalismo e a sobrevivência de

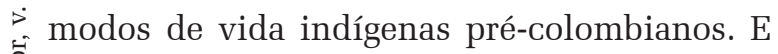
seria a combinação dessas diferentes temporalidades sociais no interior de uma divisão internacional do trabalho capitalista que tornava

ausentes, transformar-se-iam em componentes essenciais na análise de Löwy. Ver Löwy (1998, 2005) e Rubbo (2012). a sociedade peruana politicamente explosiva. ${ }^{15}$ De fato, entre a Europa Ocidental e o subcontinente latino-americano, verificava-se uma interdependência conflitiva, que demandava ser conhecida em sua especificidade. As relações de produção na história andina eram completamente diferentes da história europeia. A "recusa da ideologia do progresso e da imagem linear e eurocêntrica da história universal", traço essencial do marxismo de Mariátegui, reposicionou o dilema da revolução peruana em torno da sobrevivência do coletivismo agrário nas comunidades indígenas (Flores Galindo, [1980] 1994).

Escassos e limitados naquele momento, os estudos de viés etnográfico a que Mariátegui teve acesso, a respeito do modo de vida das comunidades indígenas pré-hispânicas (notadamente, os trabalhos de César Ugarte e de Luís Valcárcel), fez com que ele constatasse o funcionamento de uma economia agrária sem comércio e sem propriedade privada, embora marcada pela produção de excedentes econômicos. Apesar da existência de um Estado ou de um "regime autocrático dos incas", persistia, também, um conjunto de comunidades estruturadas em torno de um modo de vida tradicional coletivista, os ayllus. Nem mesmo o advento da conquista espanhola suprimiu completamente as características igualitárias da comunidade indígena herdadas dos antigos ayllus. Mariátegui denominou essa formação social de "comunismo agrário".

Independentemente do uso da terminologia e das limitações impostas ao conhecimento da sociedade inca, ${ }^{16}$ Mariátegui insistiu na persistência do "comunismo agrário" como um ritmo social e histórico que podia ser um instrumento norteador da revolução peruana. A relação entre a dominação cultural eurocêntrica e a exploração econômica capitalista do

${ }^{15}$ Michael Löwy, correspondência com Deni Alfaro Rubbo, agosto de 2017.

${ }^{16}$ Noventa anos depois, os comentadores de Mariátegui (incluindo Löwy), mesmo os mais entusiasmados, parecem coincidir que o termo "comunismo agrário" seja um dos pontos fracos do arsenal mariateguiano. Ver a famosa crítica de Paris (1966). 
campesinato indo-americano e seu modo de vida coletivista aparecia de maneira distinta daquela que marcou os pequenos proprietários camponeses na França do século XIX, fazendo com que Mariátegui percebesse os limites de uma interpretação universalista da história da transição do feudalismo ao capitalismo.

Essa ruptura teve implicações nas posições políticas defendidas por Mariátegui na primeira Conferência Comunista Latino-Americana ocorrida em 1929 em de Buenos Aires. Para a Internacional Comunista, o Peru era uma sociedade agrária "semicolonial e feudal", e o papel da burguesia "nacional" era interpretado como "progressista". A consequência prática era a defesa de uma revolução democrático-burguesa no país. Para os delegados peruanos, tendo Mariátegui à frente ${ }^{17}$ tratava-se do contrário: a sociedade peruana era marcada pela discordância entre diferentes temporalidades que transformavam o país em um explosivo barril de pólvora. Neste contexto, o coletivismo comunal poderia servir de base para a construção do socialismo no Peru por meio de uma revolução ininterrupta (Flores Galindo, [1980]1994).

\section{CONSIDERAÇÕES FINAIS}

Não por coincidência, Löwy (2013, p. 14-15) identificou uma relação de "afinidade eletiva” entre a interpretação mariateguiana das comunidades rurais indígenas e os argumentos de Marx em sua correspondência com os populistas russos, igualmente críticos da interpretação linear para o desenvolvimento do capitalismo no país. Partindo de uma interpretação da história da presença coetânea de diferentes ritmos sociais plasmando as relações sociais de produção na periferia do capitalismo mundial, a conclusão política mais importante

${ }^{17}$ Incapacitado fisicamente de participar da conferência, Mariátegui enviou duas teses, sobre a questão indígena ("O problema das raças na América Latina") e sobre a questão imperialista ("Ponto de vista anti-imperialista"), por meio de dois delegados peruanos, Hugo Pesce e Julio Portocarrero. Ver Mariátegui (1988, p. 21-86, 87-95). alcançada por Mariátegui talvez tenha sido a de assinalar a incapacidade de um desenvolvimento autônomo no Peru, dominado pelo imperialismo e pela propriedade agrária.

Ainda que Mariátegui demonstrasse certa hesitação em relação à estratégia adotada pela Internacional Comunista na China, ele se recusou a aplicar a mesma orientação na América Latina: a burguesia nacional estaria impossibilitada de encabeçar um projeto democrático e revolucionário no Peru, devido à combinação entre a fragilidade de sua posição econômica e sua inconsistência ideológica e política. A única solução encontrada, diante da combinação explosiva de ritmos sociais contraditórios na sociedade peruana, seria a de um socialismo indo-americano como parte integrante de um processo revolucionário mundial. Por todas essas características, Löwy enxergou uma profunda similaridade entre as interpretações e posições políticas de Mariátegui e a teoria da revolução permanente de Trotsky, sem deixar de destacar, ao mesmo tempo, as peculiaridades da trajetória do marxista peruano (Löwy, 1994). ${ }^{18}$

Se bem seja verdade que Löwy, ao contrário de outros marxistas "heréticos" de sua geração, como Roberto Schwarz, Francisco Weffort e Chico de Oliveira, por exemplo, não se dedicou ao desenvolvimento de uma teoria a respeito do funcionamento do capitalismo no Brasil, parece-nos que sua interpretação de Mariátegui lança luz sobre a contemporaneidade da reconstrução dessa teoria. Além disso, vale destacar que sua interpretação "trotskista" do marxista peruano pode perfeitamente ser ampliada para outras regiões da América Latina, vertebrando um programa de pesquisa a respeito das diferenças e das convergências dos processos históricos de proletarização no subcontinente.

Quando pensamos nos possíveis diálogos entre a teoria marxista da dependência

${ }^{18}$ Ao mesmo tempo criativa e polêmica, a visão "permanentista" de Löwy sobre JCM foi duramente criticada pelo sociólogo equatoriano Agustín Cueva, segundo o qual Mariátegui, na verdade, compartilhava abertamente a ideia de socialismo em um país só! Ver Cueva ([1987] 2008). 
com Mariátegui, mediados pela historiografia marxista dedicada à escravidão e à formação da classe operária de inspiração thompsoniana, que se desenvolveu na academia brasileira desde os anos 1980, ou pelo intenso trabalho etnográfico indígena, que ocupou gerações de antropólogos na Brasil e em toda a América Latina nas últimas décadas, percebemos que estamos diante da possibilidade de reinventar uma interpretação da sociedade brasileira e latino-americana cujo vértice seja a "discordância dos tempos", para lembrar a expressão de Bensaïd (1995).

Trata-se de uma tarefa cada dia mais urgente, quando pensamos nas ameaças trazidas pela terceira onda de mercantilização do trabalho, das terras e do dinheiro, e todas as implicações socialmente deletérias para os grupos e classes sociais subalternos do país. E a vivificação da teoria do desenvolvimento desigual e combinado realizada por Michael Löwy, em especial, quando pensamos em sua interpretação da trajetória de José Carlos Mariátegui, aparece entre os esforços mais promissores de reconstrução do marxismo crítico na América Latina.

Recebido para publicação em 17 de janeiro 2018

\section{REFERÊNCIAS}

ANTUNES, R. "Anotacões sobre uma bela singularidade". +i In: JINKINGS, I.; PESÇHANSKI, J. A. (Orgs.) As utopias de Michael Löwy: reflexões sobre um marxista insubordinado. São Paulo: Boitempo, 2007. p. 19-24.

¿. ARICÓ, J. (Org.) Mariátegui y las orígenes del marxismo is latinoamericano. México: Pasado y Presente, 1978.

- BEIGEL, F. La epopeya de una generación y una revista:

- las redes editoriales de José Carlos Mariátegui en America

$\ddot{m}$ Latina. Buenos Aires: Biblos, 2006.

$\therefore$ BENSAÏD, D. La discordance des temps: essais sur les oี crises, les classes, l'histoire. Paris: Éditions de la Passion, 1995 .

๙ే BOFF, L. "Prefácio". In: JINKINGS, I.; PESCHANSKI, J. A.

I (Orgs.) As utopias de Michael Löwy: reflexões sobre um marxista insubordinado. São Paulo: Boitempo, 2007. p. 156-165.

CAHEN , M.; BRAGA, R. (Orgs.) Para além do pós(-) colonial. São Paulo: Alameda, 2018.
CUEVA, A. "El marxismo latinoamericano: historia y problemas actuales". In: MOREANO, A. (Org.). Entre la ira y la esperanza y otros ensayos de crítica latinoamericana. $1^{\mathrm{a}}$. edição [1987]. Buenos Aires/ Bogotá: CLACSO - Siglo del Hombre Editores, 2008. p. 177- 200.

DEMIER, F. "A lei do desenvolvimento desigual e combinado de León Trotsky e a intelectualidade brasileira”. Outubro, São Paulo, n.16, p. 75-107, 2007.

DIANTEILL, E. "Le trois constellations Löwy - contribution à une sociologie benjaminienne de la connaissance" In: DELECROIX, V.; DIANTEILL, E. (Orgs.) Cartographie de L'utopie. L'ouvre indisciplinée de Michael Löwy. Paris: Sandre Actes, 2012. p.47-58.

DUSSEL, E. "Del último Marx a America Latina”. In:

El último Marx (1863-1882). Cidade do México: Siglo XXI, 1990. p. 238-293.

FERNANDES, F. "Prefácio". In: MARIÁTEGUI, J. C. Sete ensaios de interpretação da realidade peruana. São Paulo: Alfa Ômega, 1975.

FLORES GALINDO, A. "La agonía de Mariátegui. La polémica con la Komintern”. In: . Obras completas, $1^{\mathrm{a}}$ edição [1980]. Lima: Fundación Andina - SUR/Casa de Estudios del Socialismo, 1994. tomo IV, p. 365-511.

GARCÍA SALVATECCI, H. Sorel y Mariátegui. Lima: Delgado Vanzuela Editora, 1979.

JIMÉNEZ RICÁRDEZ, R. "Prólogo". In: MARIÁTEGUI, J. C. Obra política. Cidade do México: Ed. Era, 1978. p. 9-43.

LÖWY, M. "Dialética revolucionária contra a ideologia burguesa do progresso". In: MARX, K.; ENGELS, F. Lutas de classes na Rússia. São Paulo: Boitempo, 2013. p. 9-16.

. Entrevista por e-mail. [ago. 2017]. Entrevistador: Deni Alfaro Rubbo, São Paulo, 2017.

. Entrevista por e-mail. [ago. 2015]. Entrevistador: Deni Alfaro Rubbo, São Paulo, 2015.

. Entrevista. [nov. 2012]. Entrevistadores: Deni Alfaro Rubbo e Luiz Bernardo Pericás. São Paulo, 2012.

. A guerra dos deuses: religião e política na América Latina. Rio de janeiro: Vozes, 2000.

"Le marxisme en Amérique Latine de José Carlos Mariátegui aux zapatistes du Chiapas". Actuel Marx, [s.l.], n. 42, p.25-35, 2007.

. "Mística revolucionária: José Carlos Mariátegui e a religiã̃o". Estud. Av., São Paulo, v. 19, n. 55, p.105-116, 2005.

"Michael Löwy, entrevista concedida a Ivana

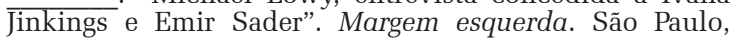
Boitempo, n. 4, p. 9-20, 2004.

A política do desenvolvimento desigual e combina do: a teoria da revolução permanente. São Paulo: Sundermann, 2015.

Pontos de referência para uma história do marxismo na América Latina. In: . (Org.) O marxismo na América Latina: uma antologia de 1909 aos dias atuais. $2^{\mathrm{a}}$ edição. São Paulo: Fundação Perseu Abramo, 2006. p. 9-66.

"A teoria do desenvolvimento desigual e combinado". Outubro, São Paulo, n. 1, p. 73-80, 1998.

Marxism and romanticism in the work of José Carlos Mariátegui. Latin American Perspectives, Riverside CA, v. 25, n. 4, p. 76-88, 1998.

"José Carlos Mariátegui et la révolution permanente". Inprécor, Paris, PECI, n. 385, 1994. Disponível em http://www.avanti4.be/debats-theoriehistoire/article/jose-carlos-mariategui-et-la-revolution. Acesso em: 01.08.2017. 
LOUREIRO, I. "Michael e Rosa". In: JINKINGS, I.; PESCHANSKI, J. A. (Orgs.) As utopias de Michael Löwy: reflexões sobre um marxista insubordinado. São Paulo: Boitempo, 2007. p. 69-76.

MARIÁTEGUI, J. C. Ideología y política. Lima: Amauta, 1988.

Siete ensayos de interpretación de la realidad peruana. Lima: Amauta, 1969.

MELIS, A. Leyendo Mariátegui. Lima: Empresa Editora Amauta, 1999.

MONTIEL, E. "Un pionnier péruvien de l'analyse sociale: José Carlos Mariátegui (1895-1930)”. Revue Internationale des Sciences Sociales, Paris, v. 31, p. 190-197, 1979.

NUÑEZ, E. La experiencia europea de José Carlos Mariátegui. Lima: Empresa Editora Amauta, 1994.

OLIVEIRA, F. Crítica à razão dualista/O ornitorrinco. São Paulo: Boitempo, 2003.

PARIS, R. La formación ideologica de Jose Carlos Mariátegui. México: Pasado y Presente, 1981.

"José Carlos Mariátegui et le modèle du 'communisme' inca". Annales. Économies, Sociétés, Civilisations, ano 21, n. 5, p. 1065-1072, 1966.

PERICÁS, L. B. "Mariátegui, os Sete Ensaios, a APRA e a Internacional Comunista”. In: ALIAGA, L.; AMORIM, H. MARCELINO, P. Marxismo: teoria, história e politica. São Paulo: Alameda, 2011.

. "José Carlos Mariátegui e o Brasil". Estud. Av., São Paulo, v. 24, n. 68, p. 335-361, 2010.
RIDENTI, M. "Romântico e errante". In: JINKINGS, I.; PESCHANSKI, J. A. (Orgs.) As utopias de Michael Löwy: reflexões sobre um marxista insubordinado. São Paulo: Boitempo, 2007. p. 167-174.

RUBBO, D. A. “'Nosso irmão mais velho’: Florestan Fernandes, leitor de Mariátegui”. Lua Nova, São Paulo, n. 99, p. 79-105, 2016.

"Marxismo, política y religión de 'un marxista convicto y confeso': Michael Löwy lector de José Carlos Mariátegui”. Herramienta, Buenos Aires, n. 51, p. 25-40, 2012

SADER, E. "Apologia da militância revolucionaria". In: JINKINGS, I;. PESCHANSKI, J. A. (Orgs.) As utopias de Michael Löwy: reflexões sobre um marxista insubordinado. São Paulo: Boitempo, 2007. p. 161-166.

SCHWARZ, R. "Aos olhos de um velho amigo". In: JINKINGS, I.; PESCHANSKI, J. A. (Orgs.) As utopias de Michael Löwy: reflexões sobre um marxista insubordinado. São Paulo: Boitempo, 2007. p. 156-165.

TRAVERSO, E. "Le marxisme libertaire de Michael Löwy". In: DELECROIX, V.; DIANTEILL, E. (Orgs.) Cartographie de L'utopie. L'ouvre indisciplinée de Michael Löwy. Paris: Sandre Actes, 2012. p. 27-38.

VANDEN. H. E. Mariátegui: influencias en su formacion ideológica. Lima: Amauta, 1975.

WEFFORT, F. O populismo na política brasileira. São Paulo: Paz e Terra, 2008 


\section{TWO MASTERS IN THE PERIPHERY OF CAPITALISM: Michael Löwy and Mariategui}

\author{
Ruy Braga \\ Deni Alfaro Rubbo
}

The purpose of this article is to discuss some of the implications of the interpretation of the unequal and combined development theory of capitalism present in several passages of Michael Löwy's work in order to indicate its importance for the critical renewal of Latin American Marxism. In order to do so, we seek to advance through three moments: 1) first, we will present the general outlines of the unequal and combined development theory in Löwy's work; 2) in the sequence, we will highlight the importance of the Latin American historical context between the years 1959 and 1979 in the interpretive and political effort of Löwy, especially for updating the theory of uneven and combined development; finally, 3) we will argue that the fecundity of Löwy's interpretation of the Latin American context stems from his familiarity with the thinking of the Peruvian Marxist José Carlos Mariátegui.

Key wORDS: Löwy. Mariátegui. Marxism. Sociology. Latin America.

\section{DEUX MAITRES DANS LA PERIPHERIE DU CAPITALISME: Michael Löwy et Mariategui}

\author{
Ruy Braga \\ Deni Alfaro Rubbo
}

Le but de cet article est de discuter de quelques-unes des implications de l'interprétation de la théorie du développement inégal et combiné du capitalisme présent dans plusieurs passages du travail de Michael Löwy afin d'indiquer son importance pour le renouveau critique du marxisme latinoaméricain.Pour faire ça, nous cherchons à avancer à travers trois moments: 1) d'abord, nous présenterons les grandes lignes de la théorie du développement inégal et combiné dans le travail de Löwy; 2) dans la séquence, nous soulignerons l'importance du contexte historique latino-américain entre les années 1959 et 1979 dans l'effort interprétatif et politique de Löwy, en particulier pour actualiser la théorie du développement inégal et combiné;enfin, 3) nous affirmons que la fécondité de l'interprétation du contexte latino-américain par Löwy découle de sa familiarité avec la pensée du marxiste péruvien José Carlos Mariátegui.

Mots-CLÉs: Löwy. Mariátegui. Marxisme. Sociologie. Amérique Latine.

Ruy Braga - Sociólogo . Livre-docente da Universidade de São Paulo . Realizou pesquisas de pósdoutorado na Universidade da Califórnia em Berkeley (2010-2011 e 2015-2016). Atuou como professor convidado nas seguintes universidades: Universidade Nacional de Cuyo (Mendoza - Argentina), Universidade de Coimbra e Universidade da Califórnia em Berkeley. Além disso, proferiu palestras e minicursos na Universidade de Roma 1 "La Sapienza”, na Universidade Nova de Lisboa, no ISCTE (Instituto Universitário de Lisboa) e na Universidade de Witwatersrand. Atualmente, é chefe do Departamento de Sociologia da Faculdade de Filosofia, Letras e Ciências Humanas da USP, onde coordena o Centro de Estudos dos Direitos da Cidadania (Cenedic).

Deni Alfaro Rubbo - Doutor em Sociologia pela Universidade de São Paulo (USP). Trabalha com temas relacionados à sociologia e história dos intelectuais, atuando principalmente nos seguintes temas: pensamento social brasileiro e latino-americano, história do marxismo, história das ciências sociais, recepção das ideias, José Carlos Mariátegui. Suas mais recentes produções são: Às voltas com o marxismo universitário paulista (Estudos Avançados, v. 32, n. 92, 2018); Heresias do marxismo brasileiro: a agonia de Caio Prado Júnior. (Estudos Avançados, v. 31, n. 90 2017); "Nosso irmão mais velho": Florestan Fernandes leitor de Mariátegui” (Lua Nova, n. 99, 2016); Párias da terra: o MST e a mundialização da luta pela camponesa. (São Paulo: Alameda/FAPESP, 2016). 